\title{
GMAT And Other Determinants Of GPA In An MBA Program
}

James W. Fairfield-Sonn, University of Hartford, USA

Bharat Kolluri, University of Hartford, USA

Rao Singamsetti, University of Hartford, USA

Mahmoud Wahab, University of Hartford, USA

\begin{abstract}
This paper reports on the influence of waiving the GMAT requirement on academic performance as measured by grade-point-average at graduation for 833 University of Hartford MBA students who graduated between 2003 and 2009. In seeking to better understand what factors might be influencing graduation GPA, we examined a variety of traditional attributes. In addition, we examined the potential influence of GMAT Waivers on graduation GPA because there was some thought that students who waived this test might have lower graduation GPAs than those who took the examination. The results of this study indicated that the most important factor for determining $M B A$ graduation GPA was an individual's undergraduate GPA, with higher undergraduate GPAs being associated with higher MBA graduation GPAs. Marginally significant differences in graduation GPA were also found based on the number of credits waived at entry into the MBA program, with more credits being waived contributing to a higher graduation GPA. We also found that women graduated with higher GPAs than men. Of particular interest to us in this study, however, was whether or not our GMAT Waiver policy was influencing graduation GPAs. In this case, we found no significant difference in graduation GPA, regardless of whether or not the GMAT requirement was waived. These results were confirmed using chi-square tests and twosample t-tests. To gain additional insights into these issues, we estimated a regression model to explain graduation GPA using several attributes as independent variables. The regression results indicate that undergraduate GPA and gender seemed to most reliably predict differences in graduation GPA.
\end{abstract}

Keywords: GMAT waiver; MBA; GPA; Hypothesis; Chi-square; t-test; Regression

\section{INTRODUCTION}

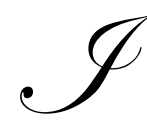
n January 2001, the Barney School of Business at the University of Hartford introduced a GMAT Waiver Policy through a formal vote by its full-time faculty. According to this policy, applicants seeking admission into the School's MBA program can request a waiver of the GMAT pre-matriculation requirement if certain criteria are met. Specifically, the Policy required that the applicant possesses at least three years of continuous meaningful work experiences to be eligible to request a GMAT Waiver. If this requirement is not met, applicants must take the GMAT and score in line with the School's minimum GMAT score requirements. However, if it is determined from a preliminary examination of the applicant's file that the applicant appears to satisfy the three-year minimum work experience requirement, the applicant can then have a formal interview with both: the School's Faculty-Person-in-Charge of the GMAT Waiver Interview Process and the Administrative Director of the MBA program. In the interview, the applicant's work experiences are thoroughly discussed and carefully evaluated so that a determination can be made as to whether or not the quality of the work experience merits a waiver of the GMAT requirement. If it is determined that the applicant possesses a convincing case for a GMAT waiver, the waiver request is granted and the applicant is allowed to fully matriculate into the MBA program. In general, the interviewers assess the applicant's professional work experiences by criteria such as: whether or not the applicant has had some mid-level management experiences, any supervisory responsibilities, and whether the applicant is or has been in some form of a decision-making capacity in his/her current or past 
organization. Based on the School's current GMAT Waiver Policy, only quantity and quality of work experiences matter; undergraduate GPA does not play a role in the decision.

The primary reason for adopting this policy was to attract more seasoned and experienced working professionals into the MBA program. That is to say; students who could enrich classroom discussions with their experience-based perspectives on business issues discussed throughout the MBA curriculum. Naturally, those students who were granted the waiver would tend to be older and more mature in comparison to students who had to take the GMAT either because they went straight into the MBA program following completion of their bachelor's degree or they didn't meet the experience requirement test. By bringing the two groups into the same classroom, the hope was to provide more diversity in the graduate student body both in terms of demographics and/or experience level. Students who have successfully met the tests of quantity and quality of work experiences that made them eligible for a GMAT waiver are generally interested in doing an MBA in order to acquire the theoretical foundation knowledge in different areas of Business either because their undergraduate degrees were in fields other than business (e.g., engineering, arts and sciences), or they have been out of school for a while and need to "refresh and retool" in order to back up their practical knowledge base gained from years of work with business education that exposes them to the latest theoretical developments. In combination, these two aspects give them a firmer ground to stand on when both theory and practice are meshed together. By bringing more experienced working professionals from the Business community into the classroom with other students who have taken the GMAT either due to lack of sufficient work experiences, or because they are foreign students ${ }^{1}$ it was perceived to contribute to rich discussions in the classroom benefitting both groups of students from each others' perspectives.

Experience from the last eight years with the GMAT Waiver Policy has shown that with this Policy we have indeed been able to attract students of good caliber, and this has enriched our student body with a mix of U.S. and International students without sacrificing the quality and rigor of the MBA Program. The GMAT Waiver policy was designed to target primarily working professionals with good experiences who are eager to take their careers to a higher level with a formal Master's degree in Business. By offering them the waiver possibility, we are providing them an opportunity to substitute work experience for taking the GMAT. The School Faculty's expectations were that individuals with strong experiences should be able to perform at a level that at least equals the level of those who took the GMAT. It is precisely this issue that is the focus of investigation in this paper. It should be noted that the GMAT Waiver Policy was subsequently extended to other Master's degree programs offered by the Barney School of Business of the University of Hartford such as: the Executive MBA Program, the Accelerated MBA Program, and the Masters of Science in Accounting and Taxation (MSAT) Program.

In addition, many believe that the adoption of this policy has also strengthened the ties of the school with the Greater Hartford Business and Non-Business communities, and fulfills an important element of the Barney School's interest in building stronger connections to our community.

The first group of students who matriculated under the GMAT Waiver Policy graduated in May 2003. Subsequently, graduations from the MBA Program occurred on a rolling basis three times a year: May, September and December. Accordingly, the dataset used in this study has undergone continual updating every semester of every year. The dataset used in this paper is the cumulative database that captures the entire Barney School's eightyear experience with the GMAT Waiver Program.

The primary research question of interest, therefore, is whether or not waiving the GMAT acted as a "drag" on students' academic performance as measured by their graduation GPA when compared to students who took the GMAT. In other words, does taking the GMAT, and the study and exam-preparation that comes with it, somehow benefit those who took it, but hurts those who waived it? For example, some claim that the mere exercise of

\footnotetext{
${ }^{1}$ The current Waiver Policy prevents foreign students from waiving the GMAT unless they can satisfy two conditions: a) they have to be present in the U.S. for an interview, and b) more importantly, they have to be eligible for an interview in the first place, a condition that can only be satisfied if they worked for one of the Global Fortune 500 Companies overseas (perhaps in their home country or a country other than the U.S.) for at least three years. These two conditions have made waiving the GMAT for foreign nationals very difficult.
} 
studying for the GMAT is beneficial because it builds up a number of analytical and language comprehension skills that students will use throughout their graduate school studies. On the other hand, others do not find evidence to substantiate that claim. Accordingly, the role that the GMAT plays in the academic preparation and performance of graduate students is a hotly-debated issue with prior studies offering conflicting conclusions. This study's aim is to contribute to this debate by using a rather large dataset, much larger than used in many previous studies, based on the University of Hartford's experience with this issue. Specifically, our dataset consists of information on 833 MBA graduates over a fairly lengthy seven year study period from May 2003 and May $2009 .^{2}$

The data used in this paper was analyzed in two ways. First, we tested a number of discrete hypotheses. Then, we built a regression model to study relationships between the dependent variable (graduation GPA) and a number of student-attributes (independent variables) such as: Gender, Undergraduate GPA, and the GMAT Scores of students who took the GMAT as opposed to those who waived it based on at least three years of work experience.

The plan of this paper is as follows. Section II presents summary descriptive statistics of the data. Section III provides a brief review of previous related studies on the topic. Section IV describes propositions and statistical tests used in this paper to test those propositions. Section V presents empirical results from tests of propositions and the results from estimating a regression model designed to explain the determinants of graduation GPA for our MBA students. Section VI contains a summary of conclusions.

\section{SUMMARY DESCRIPTIVE STATISTICS}

Table 1 presents some broad summary statistics of graduated MBA students. Of the total sample of 833 MBA graduates, $57 \%$ were male and $43 \%$ were female; $46 \%$ took the GMAT, while 54\% waived the GMAT. Of those who took the GMAT, the average GMAT score is 517 points with a standard deviation of 67 points. Per the school's course-waiver policy, only up to 18 credit-hours of waivers within which a maximum of 6 credit-hours of course transfers are allowed.

Results in Table 1 show that $58 \%$ of matriculated students were waived from some courses based on prior equivalent coursework from an AACSB-accredited institution, provided they met or exceeded our required minimum grade on courses they transferred. The average number of credit-hours waived is 6 with a standard deviation of 7 hours. A higher standard deviation of waived credits (relative to its mean) simply reflects a great deal of variation across students in number of credits waived. Last but not least, the average undergraduate GPA (UGGPA) throughout the sample is 3.08 with a standard deviation of 0.5 , which indicates that admitted students into the program, be they GMAT waivers or GMAT takers, have an acceptable undergraduate GPA.

Table 1: Summary Statistics of Some Independent Variables

\begin{tabular}{|l|c|c|c|}
\hline \multicolumn{1}{|c|}{ Independent Variables } & Percent of Total & Mean & Standard Deviation \\
\hline Male & 57 & - & - \\
\hline GMAT Taken & 46 & 517 & 67 \\
\hline Credits Waived or transferred & 58 & 6 & 7 \\
\hline Undergraduate GPA & 100 & 3.08 & 0.5 \\
\hline
\end{tabular}

Table 2 presents more descriptive statistics. Several summary statistics are presented, including proportions relative to a total of 833 students, means, standard deviations, coefficient of variation (i.e., standard deviation divided by mean), and skewness statistics for a number of attributes (variables) used in this study. As seen in Table 2 , the results suggest a fair amount of clustering of data points around the mean of a given attribute (standard deviation of an attribute is proportionately small relative to the mean of an attribute). There is a slight negative

\footnotetext{
${ }^{2}$ However it should be noted that this study is limited in the sense the sample used comes from the period when the GMAT waiver policy is in place. Therefore the results, especially with respect to the effect of GMAT are subject to this limitation and interpretation. This is due to the fact that we are unable to obtain the data prior to 2003 when the GMAT waiver policy was not in existence.
} 
skewness, but again, its magnitude is reasonably small relative to level of the attribute's mean and standard deviation, which suggests that the graduation GPA of graduated students is almost normally distributed. While on the surface, the statistics on different attributes look close, they can still reflect statistically significant variation around the mean of any given attribute. This is because the permissible range of variation in student GPAs to maintain good-standing in the MBA Program is anywhere between 3.0 and 4.0 (i.e., a 1 point difference). Therefore, a small variation in the form of one or two decimals may still statistically reflect meaningful differences on one or more attributes (variables) across the MBA student population. In view of this, formal statistical tests are required in order to draw valid conclusions on whether or not a given attribute shows statistically significant differences across the student body studied.

Table 2: Additional Summary Statistics

\begin{tabular}{|l|c|c|c|c|c|}
\hline & \multicolumn{9}{|c|}{ GPA's of graduated MBA students } & \multicolumn{1}{c|}{$\begin{array}{c}\text { Coefficient of } \\
\text { \% out of 833 }\end{array}$} & Mean & Standard Deviation & Skewness & Variation = (S.D/Mean)*100 \% \\
\hline Male & 56.9 & 3.64 & 0.20 & -0.48 & $5.49 \%$ \\
\hline Female & 43.1 & 3.69 & 0.20 & -0.82 & $5.42 \%$ \\
\hline GMAT Taken & 46.3 & 3.65 & 0.20 & -0.62 & $5.48 \%$ \\
\hline GMAT Waived & 53.7 & 3.67 & 0.20 & -0.62 & $5.45 \%$ \\
\hline <Median UGPA & 50.0 & 3.60 & 0.20 & -0.45 & $5.56 \%$ \\
\hline >=Median UGPA & 50.0 & 3.72 & 0.19 & -0.88 & $5.11 \%$ \\
\hline <=9 credits Waived & 75.0 & 3.65 & 0.19 & -0.49 & $5.21 \%$ \\
\hline$>$ 9 credits Waived & 25.0 & 3.68 & 0.21 & -0.84 & $5.71 \%$ \\
\hline
\end{tabular}

\section{LITERATURE REVIEW}

Compared to previous studies, we employ a relatively large sample of 833 graduated MBA students. For example, two studies that directly relate to ours are: Gropper (2007) who used a sample of only 180 students and three GPA measures (i.e., overall Executive MBA GPA, First-Year GPA, and Core GPA) calculated from four classes, and Wright and Palmer (1994) who used a randomly selected sample of 86 students from a total population of 201 current MBA students. Gropper (2007) examined the determinants of academic success in an Executive MBA (EMBA) Program. As a dependent variable, Gropper (2007) used three alternative performance measures: (a) first-year GPA, (b) core-four-classes GPA, and (c) overall EMBA GPA. For independent variables, he used GMAT scores, Undergraduate GPA, Gender, Work Experience, and Career Advancement. He reports both correlations and regression results, and concludes that GMAT score is not a statistically significant determinant of overall academic performance for EMBA students (Overall GPA), but that it is significant for first-year GPA. In addition, he reports that Work Experience and Career Advancement have significant positive effects on overall program performance. Additionally, he presents evidence that women perform equal to or even better than men in the EMBA program. Last but not least, he presents evidence, albeit weak evidence, that Undergraduate GPA is a good predictor of EMBA Overall GPA, and that students with an Undergraduate Engineering education do well at the graduate level. This is hardly surprising as their strong quantitative and problem solving skills tend to be strong. Anecdotally, we, at the University of Harford, can confirm a similar finding particularly with respect to Engineering students or working professional Engineers who are in our MBA Program.

Some other studies used meta-analysis to examine effects of GMAT on academic performance. MetaAnalysis is a technique that combines results from a number of studies to present a unique set of summary conclusions. This approach is similar to the concept of sampling distribution in statistical inference. For example, Kuncel, Crede and Thomas (2007) applied Meta-Analysis and reported results on the validity of the GMAT as a graduate performance indicator and concluded that GMAT is a better predictor of graduate performance than Undergraduate GPA. When combined together, however, both variables (i.e., GMAT and Undergraduate GPA) provide an even better indicator of graduate student performance. Like most studies, Kuncel et.al (2007) selected a sample from a pool of admitted students rather than studying the total applicant-pool. This is usually described as "range restriction" in sampling. In a recent study, Oh, Schmidt, Shaffer and Le (2008) re-analyzed the study of Kuncel et.al (2007) by applying a new approach that improves the accuracy of correction for range-restrictions, a 
common problem in sample selection process. They claimed that the validity of the GMAT as a performance predictor at the graduate level has been underestimated by $7 \%$ due to application of sub-optimal range- restriction correction. In one of the earlier studies, however, Wright and Palmer (1994) concluded that both GMAT scores and Undergraduate GPA were not necessarily good predictors of performance at the MBA level for "all" students, but that they could be good predictors of graduate performance particularly for students with GMAT scores and undergraduate GPAs falling in the middle range of the distributions of these variables. In view of their mixed results, based on split-sample techniques, they suggested a variety of other admission criteria should be considered such as: personal interviews, letters of recommendation, and a letter of intent which may be used to supplement GMAT score and Undergraduate GPA to provide a better set of predictors of graduate performance in the MBA Program.

\section{STATISTICAL TESTS OF HYPOTHESES}

This section presents test procedures used, sequentially, to enable us to draw firm conclusions. The first set of propositions use a series of chi-square tests to examine whether there exists: (a) any association between graduation GPA and Gender, (b) any association between graduation GPA and Number of Credit-hours waived at entry into the MBA program, (c) any association between graduation GPA and whether or not the GMAT requirement has been waived, and (d) any association between graduation GPA and Undergraduate GPA.

The second group of tests aims to garner more evidence on these issues via a series of two-sample t-tests. These tests examine whether there are statistically significant differences in performance measured by graduation GPA between: (a) males and females, (b) those waived versus not those that did not waive the GMAT, (c) those with high versus low Undergraduate GPA students (i.e., with high and low defined with respect to median Undergraduate GPA - high means above the median, and low means below the median), and (d) those who waived more than nine credits versus those who waived less than nine credits - at entry into the MBA Program — noting that nine credits is the $50^{\text {th }}$ percentile of the permissible number of credits that can be waived according to our Business School academic policies. The third and final analysis was to estimate a multiple regression model to identify determinants of graduation GPA. Here, we include a number of independent variables: (a) Undergraduate GPA, (b) Number of Credits Waived, (c) GMAT taken or Waived (a dummy variable), and (d) Gender (another dummy variable).

\section{EMPIRICAL RESULTS}

Tables 3.a, 3.b, 3.c and 3.d present results from Chi-square tests of four different hypotheses. The first tests the null hypothesis that there is no association between graduation GPA and gender with the alternate being that there is an association between the two attributes. Based on the observed p-values of the calculated chi-square statistics (Table 3.a), we confirm that performance measured by graduation GPA and Gender are significantly associated at better than the 1 percent significance level (an observed p-value of 0.21 , which is much lower than the 1 percent significance level). Results in Table 3.b suggest that there is a statistically significant association between graduation GPA and Number of credits waived. A p-value of $1.25 \%$ is obtained, indicating significance at the 5 percent level or better, which clearly rules out the null hypothesis of no relationship between graduation GPA and Number of Credits Waived. Results in Table 3.c suggest that we cannot reject the null hypothesis that there is no relationship between GPA and whether or not the GMAT is taken. The null hypothesis is not rejected at any reasonable significance level. Therefore, based on the University of Hartford's sample of 833 students, whether or not the GMAT is taken does not seem to affect graduation GPA. Last but not least, results in Table 3.d suggest that graduation GPA in the MBA Program seems to strongly depend on Undergraduate GPA (UGGPA). Indeed, the null hypothesis of no association between the two variables is rejected with almost complete certainty. Overall, test results indicate that Gender and UGGPA are very strong determinants of MBA graduation GPA, while Number of Credits Waived seems to play some role as well, marginally significant at $10 \%$. Conversely, whether or not the GMAT is taken does not seem to impact graduation GPA in any meaningful way. This last observation lends support to the idea that waiving the GMAT has not hindered performance in the University's MBA program. Indeed, the quality and quantity of work experiences seemed to have been acceptable substitutes to taking the GMAT. 
Table 3.a: Chi square tests for Independence (GPA versus Gender)

\begin{tabular}{|c|c|c|c|c|}
\hline & \multicolumn{2}{|c|}{ GENDER } & \multirow[b]{2}{*}{ Total } \\
\hline & & Males & Females & \\
\hline \multirow{2}{*}{ 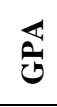 } & High & $217(239)$ & $203(181)$ & 420 \\
\hline & Low & $257(235)$ & $156(178)$ & 413 \\
\hline & Total & 474 & 359 & 833 \\
\hline
\end{tabular}

Table 3.b: GPA versus Credits Waived

\begin{tabular}{|l|l|c|c|c|}
\hline \multicolumn{2}{|c|}{} & \multicolumn{2}{c|}{ CREDITS WAIVED } & Total \\
\cline { 3 - 5 } & High & $299(315)$ & $121(105)$ & 420 \\
\cline { 2 - 5 } & Low & $325(309)$ & $88(104)$ & 413 \\
\hline & Total & 624 & 209 & 833 \\
\hline
\end{tabular}

Notes: $\chi^{2}=6.2355$ $\mathrm{p}$-value $=0.0125^{*}$

* Significant at $5 \%$ level

Table 3.c: GPA versus GMAT

\begin{tabular}{|c|c|c|c|c|}
\hline & & \multicolumn{2}{|c|}{ GMAT } & \multirow[b]{2}{*}{ Total } \\
\hline & & Taken & Waived & \\
\hline \multirow{3}{*}{ 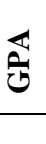 } & High & 191(195) & $229(225)$ & 420 \\
\hline & Low & $195(191)$ & $218(222)$ & 413 \\
\hline & Total & 386 & 447 & 833 \\
\hline
\end{tabular}

Notes: $\chi^{2}=0.2533 \quad$ p-value $=0.6147$

Table 3.d: GPA versus Undergraduate GPA (UGGPA)

\begin{tabular}{|l|l|c|c|c|}
\hline \multicolumn{2}{|c|}{} & \multicolumn{2}{|c|}{ UGGA } & Tow \\
\cline { 2 - 5 } & High & $260(211)$ & $160(209)$ & 420 \\
\cline { 2 - 5 } & Low & $158(207)$ & $255(206)$ & 413 \\
\hline \multirow{3}{*}{} & Total & 418 & 415 & 833 \\
\hline
\end{tabular}

Notes: $\chi^{2}=23.9281$

p-value $=0.0000 * * \quad * *$ Significant at $1 \%$ level

In all the four tables above, GPA (High) in row (1) is graduation GPA above the median level of 3.68, while GPA (Low) in row (2) is the opposite (GPA $\leq 3.68$-i.e., below the median). Further, in Table 3.d, UGGPA (High) in Column (1) represents Undergraduate GPA above the median value of 3.06, while UGGPA (Low) in Column (2) is the opposite (UGGPA $\leq 3.06$, i.e., below the median UGGPA). Finally, in all four Tables above, $(3, a)-(3 . d)$, cell frequencies are numbers of graduated students who possess that cell's characteristic and the numbers in the brackets represent expected frequencies computed under the null hypothesis of independence of row and column classifications.

To get more insights into conclusions reached from chi-squared tests, and to cross check these conclusions, we also ran two-sample t-tests. Table 4 presents results from tests of the same four similar propositions tested above. As before, the first proposition tests difference between graduation GPA's of male and female students. The very low observed p-value of $0.02 \%$ allows to confidently conclude that mean graduation GPA of female students is significantly higher than that of male students, which suggests that not only inter-dependence of Gender and graduation GPA, but also confirms that female students outperform male students with respect to GPA. The second proposition deals with whether taking or waiving the GMAT affected graduation GPA, and the results confirm the earlier conclusion from the chi-square test that there is no statistically significant association between graduation GPA of those who took versus those who waived the GMAT. This, again, supports the basic premise of the school's GMAT waiver policy and the intuition that meaningful experiences and career progression are good substitutes for 
taking the GMAT (i.e., the observed significance level - p value of 19\% - is far above the acceptable level of significance of 5\%). In sum, performance measured by graduation GPA of those who waived the GMAT did not suffer as a result of GMAT waiver policy compared to those who took it and scored well and matriculated in our MBA program. The third proposition deals with students with higher Undergraduate GPA (UGGPA) and the effect that this variable has on graduation GPA. As seen, UGGPA is perhaps the single most significant determinant of graduation GPA. Students with higher Undergraduate GPA performed better in terms of graduation GPA than students who had lower Undergraduate GPA, and this difference is statistically significant with almost complete certainty. These very strong results for Undergraduate GPA echo those reported from chi-squared tests. Finally, we conclude this section with t-test results of the proposition that students who waived at least 9 credits performed equally or at the same level as students with less than 9 credits waived. We fail to reject the null hypothesis of no difference in mean graduation GPA of the two groups at the traditional 5\% level. However, it is rejected at the 10\% level - a result that is similar to the one reported earlier in the Chi-square tests, although weaker.

Table 4: Two-Sample t-tests assuming unequal Variances (GPAs of Graduated MBA Students)

\begin{tabular}{|c|l|c|c|}
\hline Sr. No. & \multicolumn{1}{|c|}{ Null Hypothesis } & p-values & \multicolumn{1}{|c|}{ Conclusion } \\
\hline $\mathbf{1}$ & $\begin{array}{l}\text { Mean GPA for Males is at least equal to Mean } \\
\text { GPA for Females. }\end{array}$ & $0.0002 * *$ & $\begin{array}{l}\text { Mean GPA for Males is significantly lower } \\
\text { than the GPA for Females. }\end{array}$ \\
\hline $\mathbf{2}$ & $\begin{array}{l}\text { Mean GPA for those who have taken GMAT is } \\
\text { equal to the Mean GPA of those who have not } \\
\text { taken the GMAT (waived). }\end{array}$ & 0.19 & $\begin{array}{l}\text { Mean GPA is not different regardless of } \\
\text { whether or not GMAT was taken. }\end{array}$ \\
\hline $\mathbf{3}$ & $\begin{array}{l}\text { Mean GPA of those with higher UGGPA is at } \\
\text { most equal to Mean GPA of those with lower }\end{array}$ & $0.0000 * *$ & $\begin{array}{l}\text { Higher UGGPA students scored } \\
\text { significantly higher on graduation GPA than } \\
\text { those with lower UGGPA }\end{array}$ \\
\hline $\mathbf{4 G G P A}$ & $\begin{array}{l}\text { Mean GPA of students with more than or equal to } \\
\text { 9 credits waived is equal to mean GPA of students } \\
\text { with less than 9 credits waived. }\end{array}$ & $\begin{array}{l}\text { Mean GPA of students with more than 9 } \\
\text { credits waived is marginally significantly } \\
\text { different at 10\% from the Mean GPA of } \\
\text { those with less than 9 credits waived }\end{array}$ \\
\hline
\end{tabular}

Although we are able to arrive at meaningful conclusions utilizing chi-squared and t-tests, these tests have limitations as they deal with only relationships of two variables. In order to obtain a clearer picture of the influence of several determinants on graduation GPA, we employed a regression technique. A regression approach is better suited in this context since it looks at several determinants of graduation GPA at the same time, although it gives us the marginal effect of one variable at a time keeping all other variables in the model constant. Further, a regression approach gives us an idea of the contribution of the proportion of the variability in the dependent variable (graduation GPA) that is explained by the variations in the independent variables. Finally, a regression model can be used to generate predictions about the dependent variable and provides us with important test results and other summary statistics about the entire relationship between the dependent variable and the selected group of independent variables.

Table 5: Regression Results (dependent variable is Graduation (GPA of Graduated MBA Students)

\begin{tabular}{|c|c|c|}
\hline \multirow[t]{2}{*}{ Independent Variables } & \multicolumn{2}{|c|}{$\begin{array}{cl} & \text { Regression Model: } \\
\text { GGPA }=\alpha+\beta_{1} \mathrm{D} 1+\beta_{2} \mathrm{X} 1+\beta_{3} \mathrm{D} 2+\beta_{4} \mathrm{X} 2+\varepsilon\end{array}$} \\
\hline & Coefficients & P-values \\
\hline Intercept & 3.2949 & $0^{* *}$ \\
\hline Gender Dummy D1 & -0.0307 & $0.0223^{*}$ \\
\hline Undergrad GPA X1 & 0.1286 & $8.319 \mathrm{E}-19^{* * *}$ \\
\hline GMAT Dummy D2 & -0.0168 & 0.2126 \\
\hline Total Credits waived X2 & -0.0009 & 0.4193 \\
\hline $\mathbf{R}^{2}$ & \multicolumn{2}{|c|}{0.1105} \\
\hline Adjusted $\mathrm{R}^{2}$ & \multicolumn{2}{|c|}{0.1062} \\
\hline Significance of $F$-value & \multicolumn{2}{|c|}{$4.1918 \mathrm{E}-20^{* *}$} \\
\hline
\end{tabular}


Table 5 presents regression results. The regression equation consists of Gender (D1), Undergraduate GPA (X1), GMAT (D2), and Credits Waived (X2) as independent variables. The significance level associated with the Fstatistic shows the model is highly significant and it can be used for inference and prediction of the graduation GPA. The coefficient of determination $\left(\mathrm{R}^{2}\right)$ for the model suggests that the independent variables considered together explain $11 \%$ of the variation in the dependent variable graduation GPA. While this $\mathrm{R}^{2}$ coefficient seems low, it is not uncommon, particularly in studies of this nature, since other independent variables, such as ability (IQ), effort (hours studied), age, types of experiences, and methods of grading, are not included in the model. Some of these attributes may be difficult to measure in a reliable way, while others may be easy to measure. In any event, they were not available to us at this point and we make extension of the model to include additional attributes an issue for future research. Further, previous studies have not shown greater luck in achieving a higher model explanatory power, $\mathrm{R}^{2}$. For example, Gropper (2007) reported $\mathrm{R}^{2}$ values ranging from $0.5 \%$ to a maximum of $15 \%$, the latter not being much higher than what we found in our study. Looking at the effect of the independent variable, UGGPA (X1), it remains to be consistently significant and possesses the correct sign (a positive coefficient). This coefficient can be interpreted to imply that for every $1 \%$ increase in UGGPA, there is an increase in graduation GPA by $13 \%$ holding all other variables constant. Similarly, Gender (a dummy variable D1) is significant. The estimate of -0.0307 for Gender indicates that males' performance is lower by 0.0307 , on average, compared to females' graduation GPA. This is consistent with previous findings that generally female students outperform male students.

With respect to the effect of the number of credits(X2) waived on graduation GPA, we did not find any statistical significance. This is somewhat contrary to our findings in Chi-square test in Table $3 \mathrm{~b}$ and in the twosample t-test in Table 4 (row 4). Thus, with regard to the number of credits waived, we are unable to arrive at any definitive conclusion.

\section{SUMMARY OF CONCLUSIONS}

This paper examined several factors that can potentially influence student academic performance in the MBA Program of the Barney School of Business of the University of Hartford, as measured by graduation GPA. A number of research techniques were used to provide answers to the research questions of interest. A unique data set comprising 833 graduated MBA students over the course of the last eight years, 2001 to 2009, was utilized. Alternative statistical tests were conducted on a number of propositions tested and the results from different tests are remarkably consistent. The following summarizes the results. First, graduation GPA of female students is significantly higher than that of male students. Second, we were unable to identify any causal relationship between whether or not the GMAT was taken and graduation GPA. Indeed, whether the GMAT is taken or not does not seem to affect the outcome - graduation GPA. This evidence validates the practice of the School's GMAT waiver policy and provides support to the idea that meaningful work experiences, as an alternative to taking the GMAT, may be considered a reasonable substitute for taking the GMAT. Third, students with higher Undergraduate GPA performed better had higher graduation GPAs than those with lower Undergraduate GPAs. Fourth, the Number of Credits Waived showed mixed results on graduation GPA in terms of its statistical significance. In the regression model, this particular variable was statistically insignificant although in earlier tests, it indicated some influence effecting graduation GPA.

\section{AUTHOR INFORMATION}

James W. Fairfield-Sonn, Ph.D. is a tenured Professor of Management at the Barney School of Business at the University of Hartford. At this AACSB accredited Business School, he was Chair of the Management Department from 1987-1990, Director of the Executive MBA Program from 1993-1995, and in 1999, won the first "Outstanding Teacher of the Year" Award. Currently, he teaches courses in Leadership and Management, Managerial Skills, and Process and Project Management. His research interests center on understanding how corporate culture and quality practices influence organizational performance. In addition to lecturing throughout the United States and Europe on these topics, he has also published his findings in many journals and recently authored a book on the subject entitled, Corporate Culture and the Quality Organization. He has consulted with firms in the fields of: architecture, chemicals, computers, defense, education, engineering, finance, health care, insurance, law, restaurants, and utilities. Jim received his B.S. degree from the University of Massachusetts (Amherst), M.S. from Cornell's School of Industrial and Labor Relations, and Ph.D. from Yale. 
Bharat R. Kolluri is Professor of Economics, Department of Economics, Finance, and Insurance at the University of Hartford. His articles have appeared in journals such as Journal of Macroeconomics, The Southern Economic Journal, and The Review of Economics and Statistics. He presented papers in a number of professional organizations including Financial Management Association, and International Symposium on Forecasting. At present he is working on the linkages between common stock returns and the bond returns.

Rao Singamsetti, after teaching economics for ten years in the Andhra University, India, went to SUNY, Buffalo, New York and earned Ph.D. in Economics. He joined the faculty of the AACSB accredited, Barney School of Business of the University of Hartford. He is now Associate Professor of Economics in the Department of Economics, Finance and Insurance. His articles appeared in journals like the American Journal of Business Education, Journal of Productivity Analysis, Journal of Statistical Planning and Inference, Southern Economic Journal, International Journal of Industrial Organization, Explorations in Economic Research.

Dr. Mahmoud Wahab is Professor of Finance at the University of Hartford. He is also a CFA since 1992. He has published numerous articles in mainstream academic Finance Journals in the areas of International Investments, Capital Markets, and Derivatives. His work is published in Journals such as: Journal of International Money and Finance, Journal of Portfolio Management, Journal of Futures Markets, The Financial Review, Global Finance Journal, Journal of International Financial Markets, Institutions and Money, International Review of Economics and Finance, Review of Quantitative Finance and Accounting, and Applied Economics to name a few. He serves as an ad-hoc reviewer for several mainstream finance journals, and he has been with University of Hartford since 1990. His research interests are in the areas of Securities Markets, Derivatives, International Finance and Investments.

\section{REFERENCES}

1. Gropper, Daniel M. 2007. Does the GMAT matter for Executive MBA students? Some Empirical Evidence. Academy of Management Learning \& Education, 6(2):206-216

2. Kuncel, N.R., Credé, M., \& Thomas, L.L. 2007. A meta-analysis of the predictive validity of the Graduate Management Admission Test (GMAT) and undergraduate grade point average (UGPA) for graduate student academic performance. Academy of Management Learning \& Education, 6(1):51-68.

3. Oh, In-Sue., Frank L. Schmidt, Jonathan A. Shaffer, \& Huy Le. 2008. The Graduate Management Admission Test (GMAT) is even more valid than we thought: A new development in meta-analysis and its implications for the validity of the GMAT. Academy of Management Learning \& Education, 7(4): 563-570

4. Wright, Robert E., \& John C. Palmer, 1994. GMAT scores and undergraduate GPAs as predictors of performance in graduate business programs Journal of Education for Business. Washington 69(6): P344 
NOTES 